\title{
Impact of body mass index on the incidence and severity of post-endoscopic retrograde cholangiopancreatography pancreatitis
}

\author{
Mohamed M. Abdelfatah ${ }^{\mathrm{a}, \mathrm{b}}$, Nicholas J. Koutlas ${ }^{\mathrm{a}}$, Eric Gochanoura, Ahmed Hamed ${ }^{\mathrm{a}}$, Mariam Ibrahim ${ }^{\mathrm{a}}$, \\ Mohamed Barakat', Prashant R. Mudireddy ${ }^{\mathrm{a}}$
}

East Carolina University, Greenville, NC; Emory University, Atlanta, GA, USA

\section{Abstract}

\section{Introduction}

Acute pancreatitis is a major complication after endoscopic retrograde cholangiopancreatography (ERCP). The incidence of post-ERCP pancreatitis (PEP) ranges from $1-9 \%$ in

Division of Gastroenterology, Hepatology and Nutrition, Department of Internal Medicine, ${ }^{a}$ East Carolina University, Greenville, NC (Mohamed M. Abdelfatah, Nicholas J. Koutlas, Eric Gochanour, Ahmed Hamed, Mariam Ibrahim, Prashant R. Mudireddy); 'Emory University, Atlanta, GA (Mohamed M. Abdelfatah), USA; 'The Brooklyn Hospital Center, Bbrooklyn, NY (Mohamed Barakat), USA

Conflict of Interest: None

Correspondence to: Mohamed M. Abdelfatah, MD, Department of Internal Medicine, Division of Gastroenterology, Hepatology, and Nutrition, Emory University, 1365 Clifton Road, NE, Atlanta, Georgia 30322, USA, e-mail: mohamed.magdy@emory.edu

Received 15 December 2018; accepted 11 February 2019; published online 12 March 2019

DOI: https://doi.org/10.20524/aog.2019.0367 average-risk patients [1] and from 11-40\% in high-risk patients, with a $0.1 \%$ mortality risk related to pancreatitis and an annual healthcare expenditure totaling $\$ 199$ million in the United States [2-9].

Risk factors for PEP have been studied extensively and are classified into patient- and procedure-related factors. Procedure-related risk factors include difficult or failed biliary cannulation, biliary sphincter balloon dilatation, pancreatic sphincterotomy and pancreatic duct injection. Patient-related factors such as young age, female sex, suspected sphincter of Oddi dysfunction, history of recurrent pancreatitis, history of prior PEP, and absence of chronic pancreatitis have all been shown to increase the likelihood of PEP [10-13]. Identification of these risk factors has allowed clinicians to risk-stratify patients and determine if PEP prophylaxis is necessary.

Studies have shown that obesity may contribute to the incidence, severity and mortality of acute pancreatitis [14-17]. This is presumably due to the chronic low-grade inflammatory state that has been observed in obese patients [18]. Obesity is also associated with decreased levels of adiponectin, an anti-inflammatory adipokine that may be a protective factor 
for acute pancreatitis [19]. Additionally, peripancreatic and retroperitoneal fat deposits could be susceptible to fat necrosis and increase the risk of additional local complications of acute pancreatitis, such as abscesses and pseudocysts [15].

The correlation between obesity and the incidence and severity of PEP has not yet been elucidated. A larger retrospective study of 964 patients by Deenadayalu et al showed that rates of PEP did not differ between patients with a body mass index $(\mathrm{BMI}) \geq 30 \mathrm{~kg} / \mathrm{m}^{2}$ and those with $\mathrm{BMI}<30 \mathrm{~kg} / \mathrm{m}^{2}(12.5 \%$ vs. $16.4 \%$, respectively, $\mathrm{P}=0.14$ ).

In contrast, Cotton et al showed that obesity is associated with post-ERCP complications, including PEP [20]. To complicate things further, a recent retrospective study of 583 patients by Fujisawa et al demonstrated that obese patients $\left(\mathrm{BMI} \geq 30 \mathrm{~kg} / \mathrm{m}^{2}\right)$ had a significantly higher rate of PEP compared to overweight (BMI $25-30 \mathrm{~kg} / \mathrm{m}^{2}$ ), normal-weight (BMI 18.5$\left.25 \mathrm{~kg} / \mathrm{m}^{2}\right)$, and underweight $\left(\mathrm{BMI}<18.5 \mathrm{~kg} / \mathrm{m}^{2}\right)$ patients. However, one of the limitation of the Fujisawa et al study that only 20 patients were obese [21]. Furthermore, Kumar et al performed a national database analysis that was suggestive of a positive correlation between obesity and PEP (odds ratio [OR] $1.55,95 \%$ confidence interval [CI] 1.25-1.92) [24].

While numerous studies have examined the relationship between obesity and acute pancreatitis, far less is known about low BMI and acute pancreatitis, let alone PEP. Fujisawa et al reported that underweight patients $(B M I<18.5)$ had higher rates of PEP compared to normal-weight individuals (BMI 18.5-25). There was no difference in the severity of PEP between normal- and underweight patients [19]. In comparison, a study by Deenadayalu et al examined the incidence of PEP in patients with $\mathrm{BMI}<20$ and found no increase in PEP [21]. In this study, we aimed to better clarify the relationship between BMI and the incidence and severity of PEP.

\section{Patients and methods}

After approval by the University and Medical Center Institutional Review Board at East Carolina University/ Vidant Medical Center, we conducted a retrospective study of all ERCPs performed at the Center from January 2009 to October 2016. The study included all patients who underwent diagnostic or therapeutic ERCP within the study period.

The procedures were performed by 4 experienced endoscopists. All patients underwent ERCP with a standard duodenoscope (JF 260 or 260V; Olympus Optical Co., Ltd., Tokyo, Japan). Patient characteristics and procedural details were collected. Patients noted to have had acute pancreatitis within $72 \mathrm{~h}$ before the procedure were excluded from the study.

We reviewed patient demographic information, relevant medical history and home medications. All available laboratory blood work, pre- and post-procedure imaging studies, and follow-up documentation were also reviewed. Procedure details, including sphincterotomy, biopsy, stent placement/ removal, cannulation of the common bile duct, cannulation of the main pancreatic duct, cholangiogram, and pancreatogram were noted. Type and size of any endobiliary stent were noted, along with information on other interventions performed during the ERCP.

\section{Follow up}

All the documented complications of ERCP in the electronic health record from subsequent admissions, emergency room or follow-up clinic visits, nurse's post-procedure phone calls and notifications of admission to another hospital or emergency room were reviewed. Complications were collected, including post-ERCP pancreatitis, end-organ damage, pancreatic necrosis, and death.

\section{Definitions}

BMI was classified according to the World Health Organization's definition: underweight, $\mathrm{BMI}<18.5 \mathrm{~kg} / \mathrm{m}^{2}$; normal weight, BMI $18.5-25 \mathrm{~kg} / \mathrm{m}^{2}$; obese, BMI $30-40 \mathrm{~kg} / \mathrm{m}^{2}$; morbidly obese, $\mathrm{BMI} \geq 40 \mathrm{~kg} / \mathrm{m}^{2}$.

PEP was defined as new-onset or worsening abdominal pain causing an unplanned admission following an outpatient ERCP, or prolongation of a hospital stay following an ERCP. This diagnosis was associated with an increase in serum lipase or amylase levels to at least 3-fold greater than normal approximately $24 \mathrm{~h}$ after the procedure [15].

The severity of PEP was graded according to the revised Atlanta classification: mild, no evidence of organ failure or local or systemic complications; moderate, transient organ failure, or local or systemic complications in the absence of persistent organ failure; or severe, persistent organ failure or pancreatic necrosis. High-risk ERCP was defined based on prospectively validated patient and procedure-related independent risk factors [16-20].

\section{Outcomes}

The primary outcome of interest was the incidence of PEP in consecutive ERCPs. The secondary outcome of interest was the severity of PEP.

\section{Statistical analysis}

Continuous variables were evaluated using Student's $t$-test and categorical variables using Fisher's exact test. Patients with $\mathrm{BMI} \geq 30 \mathrm{~kg} / \mathrm{m}^{2}$ were compared with those with $\mathrm{BMI}<30 \mathrm{~kg} / \mathrm{m}^{2}$. Univariate logistic regression analysis of clinical and procedural factors associated with PEP was then conducted, with PEP as the dependent variable and the following independent variables: age, sex, BMI, rectal indomethacin administration, procedure indication, bilirubin level, prior pancreatitis, prior PEP, cannulation of pancreatic duct with contrast, pancreatic or biliary sphincterotomy, difficult cannulation, brush/cytology, biopsy, stent placement, balloon dilation and stone extraction. 
All mutually exclusive variables associated with PEP $(\mathrm{P}<0.1)$ in the univariate analysis were included in the multivariate logistic regression model. Statistical analysis was carried out using JMP software (v10; SAS Institute Inc., Cary, NC).

\section{Results}

A total of 2236 patients whose BMI was recorded and who had adequate follow up were included in the final analysis. The average patient age was $60 \pm 18$ years; 1247 (56\%) patients were female, and 991 (44\%) were male. The average BMI was $29 \pm 8\left(\mathrm{~kg} / \mathrm{m}^{2}\right)$. Procedure risk factors did not differ between the 2 groups.

\section{Study outcome}

Overall, $17 \%$ of the patients who underwent ERCP were high-risk for PEP. PEP was diagnosed in 107 (4.8\%) patients. In total, 921 patients had $\mathrm{BMI} \geq 30 \mathrm{~kg} / \mathrm{m}^{2}$ while 1315 patients had $\mathrm{BMI}<30 \mathrm{~kg} / \mathrm{m}^{2}$. There was no statistically significant difference in the procedure or patients' risk factors between the patients in the low- $\left(<30 \mathrm{~kg} / \mathrm{m}^{2}\right)$ and high-BMI $\left(\geq 30 \mathrm{~kg} / \mathrm{m}^{2}\right)$ groups. Of the 921 patients with $\mathrm{BMI} \geq 30,49$ were diagnosed with PEP (5.3\%). In comparison, 58 patients (4.4\%) were diagnosed with $\mathrm{PEP}$ of the 1317 patients with $\mathrm{BMI}<30 \mathrm{~kg} / \mathrm{m}^{2}$ (odds ratio [OR] $1.2,95 \% \mathrm{CI} 0.82-1.8 ; \mathrm{P}=0.32$ ). There was no difference in the incidence of PEP in BMI subgroups (Fig. 1).

In the univariate analysis, the following factors were associated with PEP: female aged $<40$ years, biliary sphincterotomy, pancreatic sphincterotomy, cannulation of the main pancreatic duct, contrast injection into the pancreatic duct (limited and complete pancreatogram), difficult cannulation, failed pancreatic duct stent placement, and a history of recurrent acute pancreatitis (Table 1).

In the multivariate model, female sex and $<40$ years of age, biliary sphincterotomy, pancreatic sphincterotomy, contrast injection into the pancreatic duct (limited and complete pancreatogram), difficult cannulation, and failed pancreatic duct stent placement were associated with PEP. However, $\mathrm{BMI} \geq 30$ did not impact the incidence of PEP (OR 1.1, 95\%CI $0.75-1.8 ; \mathrm{P}=0.48$ ) (Table 2). Likewise, there was no difference in the incidence of PEP in the subgroup analysis of different BMI categories (Table 3).

\section{Severity of PEP}

Seven patients were diagnosed with moderately severe pancreatitis according to the revised Atlanta classification: one in the underweight group, two in the normal BMI group, three in the overweight group and one in the morbidly obese group.

Nine patients were diagnosed with severe pancreatitis: 1 in the underweight group, 2 in the normal BMI group, 1 in the overweight group, 3 in the obese group, and 2 in the morbidly obese group. Three of the 9 patients died within 30 days: 1 in the morbidly obese group, 1 in the obese group, and 1 in the normal BMI group.

\section{Discussion}

Results from our study indicated that increased BMI $\left(\geq 30 \mathrm{~kg} / \mathrm{m}^{2}\right)$ does not increase the risk of PEP. Furthermore, different subcategories of BMI, including underweight, overweight, obese and morbidly obese, are not associated with a different incidence of PEP compared to normal-weight patients. Our results were consistent with those of Deenadayalu et al [21].

Likewise, our study clearly demonstrates that an increase or decrease in BMI does not impact the severity of PEP. We used the revised Atlanta classification to categorize the severity of PEP [22]. Persistent organ failure and necrosis were distributed equally between the obese and non-obese patients. Our results differ from observational studies that suggest obesity increases the incidence, severity, and mortality of acute pancreatitis [14-17]. This may be explained by differences

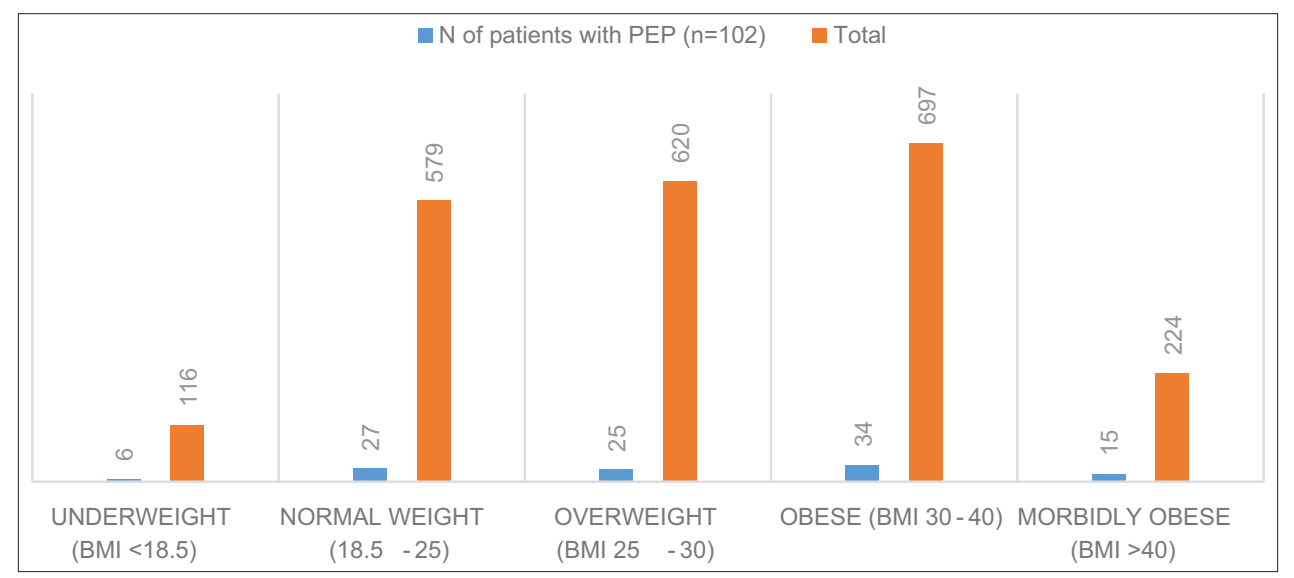

Figure 1 The number of PEP in each of the BMI subgroups

$P E P$, post-endoscopic retrograde cholangiopancreatography pancreatitis; BMI, body mass index 
Table 1 Incidence of PEP according to risk factors

\begin{tabular}{|c|c|c|c|}
\hline Risk factors & PEP n (\%) & $\mathrm{P}$ & OR $(95 \% \mathrm{CI})$ \\
\hline Female sex & $68 / 1246(5.5)$ & 0.09 & $0.7(0.47-1.1)$ \\
\hline Female $<40$ years & $19 / 257(7.4)$ & $0.05^{*}$ & $1.7(1.0-2.9)$ \\
\hline Body mass index $(\mathrm{BMI}) \geq 30$ & $49 / 921(5.3)$ & 0.32 & $1.2(0.8-1.8)$ \\
\hline Normal bilirubin & $51 / 1171(4.4)$ & 0.31 & $1.2(0.8-1.8)$ \\
\hline History of PEP & $3 / 58(5.2)$ & 0.89 & $1.0(0.3-3.5)$ \\
\hline History of recurrent pancreatitis & $11 / 121(9)$ & $0.002^{*}$ & $2.6(1.3-5.1)$ \\
\hline Difficult cannulation & $48 / 500(9.6)$ & $0.0001^{*}$ & $5.6(3.7-8.6)$ \\
\hline Biliary sphincterotomy & $74 / 1064(7)$ & $0.000^{*}$ & $2.5(1.7-3.9)$ \\
\hline Biliary stent insertion & $41 / 787(5.2)$ & 0.49 & $1.2(0.8-1.6)$ \\
\hline Cannulation of MPD & $57 / 658(8.7)$ & $0.000^{*}$ & $2.9(2-4)$ \\
\hline Cannulation of MPD with wire only & $17 / 251(6.7)$ & 0.14 & $1.5(0.9-2.6)$ \\
\hline Limited pancreatogram & 19/144 (13.2) & $0.000^{*}$ & $3.5(2.0-5.9)$ \\
\hline Complete pancreatogram & 20/197 (10.2) & $0.001^{*}$ & $2.5(1.5-4.2)$ \\
\hline Pancreatic sphincterotomy & $12 / 67(18)$ & $0.000^{*}$ & $4.8(2.5-9.2)$ \\
\hline Pancreatic duct dilatation & $3 / 56(5.4)$ & 0.87 & $1.1(0.34-3.6)$ \\
\hline Failed PDS placement & $8 / 17(47)$ & $0.0001^{*}$ & $19(7.2-50)$ \\
\hline EUS FNA of the pancreas & $12 / 161(7.5)$ & 0.12 & $1.3(0.9-3.1)$ \\
\hline
\end{tabular}

\section{${ }^{*} \mathrm{P}$ value $<0.05$}

ERCP, endoscopic retrograde cholangiopancreatography; PEP, post-ERCP pancreatitis; OR, odds ratio; CI, confidence interval; BMI, body mass index; MPD, main pancreatic duct; PDS, pancreatic duct stent; EUS FNA, endoscopic ultrasound fine-needle aspiration

Table 2 Factors associated with PEP, multivariate analysis

\begin{tabular}{lcc}
\hline Factors & OR $(95 \% \mathrm{CI})$ & $\mathrm{P}$ \\
\hline Female $<40$ years & $1.8(1.0-3.1)$ & $0.04^{*}$ \\
$\begin{array}{l}\text { Cannulation of pancreatic duct, } \\
\text { limited pancreatogram }\end{array}$ & $3.5(1.8-6.0)$ & $0.001^{*}$ \\
$\begin{array}{l}\text { Cannulation of pancreatic duct, } \\
\text { complete pancreatogram }\end{array}$ & $2.6(1.3-4.8)$ & $0.001^{*}$ \\
Difficult cannulation & $2.6(1.7-4)$ & $0.001^{*}$ \\
Biliary sphincterotomy & $3(1.9-4.7)$ & $0.001^{*}$ \\
Pancreatic sphincterotomy & $2.6(1.1-5.6)$ & $0.03^{*}$ \\
\hline Failed pancreatic duct stent placement & $13(4.0-41)$ & $0.001^{*}$ \\
\hline Recurrent pancreatitis & $1.4(0.7-3)$ & 0.29 \\
\hline BMI $\geq 30 \mathrm{~kg} / \mathrm{m}^{2}$ & $1.2(0.8-1.8)$ & 0.49 \\
\hline${ }^{*}<0.05$ & &
\end{tabular}

ERCP, endoscopic retrograde cholangiopancreatography; PEP, post-ERCP pancreatitis; OR, odds ratio; CI, confidence interval; BMI, body mass index

in the etiology and mechanism of acute pancreatitis (such as alcohol or hypertrygliceridemia) and PEP. It has been suggested that local injury to the papilla from instrumentation, sphincterotomy or forceful and repetitive injection of contrast causes papillary edema or spasm. This is thought to result in ductal hypertension followed by reduced pancreatic duct drainage. The poor drainage initiates an inflammatory cascade, promoting intraluminal activation of proteolytic enzymes and autodigestion of the pancreas. Significant release of cytokines
Table 3 Incidence of PEP by BMI groups

\begin{tabular}{lcc}
\hline BMI $\left(\mathrm{kg} / \mathrm{m}^{2}\right)$ & $\begin{array}{c}\text { No. of patients } \\
\text { with PEP } \\
(\mathrm{N}=102)\end{array}$ & $\begin{array}{c}\text { RR }(95 \% \mathrm{CI}) \\
\text { P-value vs. normal } \\
\text { weight }\end{array}$ \\
\hline Underweight $(\mathrm{BMI}<18.5)$ & $6 / 116(4.6)$ & $1(0.4-2.6) \mathrm{P}=0.8$ \\
\hline Normal weight $(18.5-25)$ & $27 / 579(4.7)$ & \\
\hline Overweight (BMI 25-30) & $25 / 620(4)$ & $0.9(0.5-1.4) \mathrm{P}=0.6$ \\
Obese (BMI 30-40) & $34 / 697(4.8)$ & $1.0(0.6-1.7) \mathrm{P}=0.85$ \\
\hline Morbidly obese (BMI >40) & $15 / 224(7)$ & $1.4(0.8-2.6) \mathrm{P}=0.26$ \\
\hline $\begin{array}{l}\text { ERCP, endoscopic retrograde cholangiopancreatography; } \text { PEP, post-ERCP } \\
\text { pancreatitis; BMI, body mass index; } \text { RR, risk ratio; CI, confidence interval }\end{array}$
\end{tabular}

(interleukin $-1,-6$, and -8 ) results in a systemic inflammatory response with multiorgan involvement $[8,23]$.

There are several strengths to our study, including the large sample size. Given the relatively low incidence of PEP, a large sample size is imperative for the study to have enough power to detect differences in PEP between various BMI groups. To date, this is the largest retrospective study to investigate the relationship between PEP and BMI. Another strength of our study is the comprehensive dataset, which includes all possible confounders and the use of univariate and multivariate analyses to accurately define the impact of BMI on PEP.

The study has a few notable limitations. First, BMI was used as a surrogate for obesity. BMI is imperfect, as it uses weight rather than body composition and therefore cannot distinguish between adiposity and increased muscle mass. Second, while 


\section{Summary Box}

\section{What is already known:}

- Acute pancreatitis is a major complication following endoscopic retrograde cholangiopancreatography (ERCP)

- Procedure-related risk factors for post-ERCP pancreatitis (PEP) include difficult or failed biliary cannulation, biliary sphincter balloon dilatation, pancreatic sphincterotomy, and pancreatic duct injection

- Patient-related factors include young age, female sex, suspected sphincter of Oddi dysfunction, history of recurrent pancreatitis, history of prior PEP, and absence of chronic pancreatitis

\section{What the new findings are:}

- Obesity does not increase the incidence or severity of PEP

- Low body mass index does not impact the incidence or severity of PEP

our study had a large sample size, it was retrospective in design and was thus susceptible to confounding. We attempted to adjust for this using univariate and multivariate analysis to detect any confounding variables.

In conclusion, our study showed no correlation between obesity and the incidence or severity of PEP. Likewise, patients classified as underweight did not have a higher incidence or severity of PEP. Future studies on this topic should ideally be performed prospectively to minimize bias and should use other measures of body composition to better evaluate obesity status.

\section{References}

1. Freeman ML, Guda NM. Prevention of post-ERCP pancreatitis: a comprehensive review. Gastrointest Endosc 2004;59:845-864.

2. Kochar B, Akshintala VS, Afghani E, et al. Incidence, severity, and mortality of post-ERCP pancreatitis: a systematic review by using randomized, controlled trials. Gastrointest Endosc 2015;81:143-149.

3. Wang AY, Strand DS, Shami VM. Prevention of post-endoscopic retrograde cholangiopancreatography pancreatitis: medications and techniques. Clin Gastroenterol Hepatol 2016;14:1521-1532.

4. Andriulli A, Loperfido S, Napolitano G, et al. Incidence rates of post-ERCP complications: a systematic survey of prospective studies. Am J Gastroenterol 2007;102:1781-1788.

5. Freeman ML, Nelson DB, Sherman S, et al. Complications of endoscopic biliary sphincterotomy. NEngl J Med 1996;335:909-918.
6. Freeman ML, DiSario JA, Nelson DB, et al. Risk factors for postERCP pancreatitis: a prospective, multicenter study. Gastrointest Endosc 2001;54:425-434.

7. Sherman S, Lehman GA. ERCP- and endoscopic sphincterotomyinduced pancreatitis. Pancreas 1991;6:350-367.

8. Sherman S, Ruffolo TA, Hawes RH, Lehman GA. Complications of endoscopic sphincterotomy. A prospective series with emphasis on the increased risk associated with sphincter of Oddi dysfunction and nondilated bile ducts. Gastroenterology 1991;101:1068-1075.

9. Cotton PB, Lehman G, Vennes J, et al. Endoscopic sphincterotomy complications and their management: an attempt at consensus. Gastrointest Endosc 1991;37:383-393.

10. Andrade-Dávila VF, Chávez-Tostado M, Dávalos-Cobián C, et al. Rectal indomethacin versus placebo to reduce the incidence of pancreatitis after endoscopic retrograde cholangiopancreatography: results of a controlled clinical trial. BMC Gastroenterol 2015;15:85.

11. Elmunzer BJ, Scheiman JM, Lehman GA, et al; U.S. Cooperative for Outcomes Research in Endoscopy (USCORE). A randomized trial of rectal indomethacin to prevent post-ERCP pancreatitis. N Engl J Med 2012;366:1414-1422.

12. Freeman ML. Pancreatic stents for prevention of post-endoscopic retrograde cholangiopancreatography pancreatitis. Clin Gastroenterol Hepatol 2007;5:1354-1365.

13. Rustagi T, Jamidar PA. Endoscopic retrograde cholangiopancreatography (ERCP)-related adverse events: postERCP pancreatitis. Gastrointest Endosc Clin N Am 2015;25:107-121.

14. Abu Hilal M, Armstrong T. The impact of obesity on the course and outcome of acute pancreatitis. Obes Surg 2008;18:326-328.

15. Martínez J, Sánchez-Payá J, Palazón JM, Suazo-Barahona J, Robles-Díaz G, Pérez-Mateo M. Is obesity a risk factor in acute pancreatitis? A meta-analysis. Pancreatology 2004;4:42-48.

16. Hong S, Qiwen B, Ying J, Wei A, Chaoyang T. Body mass index and the risk and prognosis of acute pancreatitis: a meta-analysis. Eur J Gastroenterol Hepatol 2011;23:1136-1143.

17. Krishna SG, Hinton A, Oza V, et al. Morbid obesity is associated with adverse clinical outcomes in acute pancreatitis: a propensitymatched study. Am J Gastroenterol 2015;110:1608-1619.

18. Papachristou GI, Papachristou DJ, Avula H, Slivka A, Whitcomb DC. Obesity increases the severity of acute pancreatitis: performance of APACHE-O score and correlation with the inflammatory response. Pancreatology 2006;6:279-285.

19. Fujisawa T, Kagawa K, Hisatomi K, et al. Obesity with abundant subcutaneous adipose tissue increases the risk of post-ERCP pancreatitis. J Gastroenterol 2016;51:931-938.

20. Cotton PB, Garrow DA, Gallagher J, Romagnuolo J. Risk factors for complications after ERCP: a multivariate analysis of 11,497 procedures over 12 years. Gastrointest Endosc 2009;70:80-88.

21. Deenadayalu VP, Blaut U, Watkins JL, et al. Does obesity confer an increased risk and/or more severe course of post-ERCP pancreatitis?: a retrospective, multicenter study. J Clin Gastroenterol 2008; 42:1103-1109.

22. Banks PA, Bollen TL, Dervenis C, et al; Acute Pancreatitis Classification Working Group. Classification of acute pancreatitis-2012: revision of the Atlanta classification and definitions by international consensus. Gut 2013;62:102-111.

23. Pezzilli R, Romboli E, Campana D, Corinaldesi R. Mechanisms involved in the onset of post-ERCP pancreatitis. JOP 2002;3:162-168.

24. Kumar N, Gergi MA, Thompson CC. Obesity is an independent risk factor for post-ERCP pancreatitis: results of a nationwide database analysis. Gastrointest Endosc 2012;75:AB142. 